Binner, Richard; Homberg, Ulrike; Prohaska, Steffen; Kalbe, Ute; Witt, Karl Josef Identification of Descriptive Parameters of the Soil Pore Structure using Experiments and CT Data

Verfügbar unter / Available at:

https://hdl.handle.net/20.500.11970/100296

Vorgeschlagene Zitierweise / Suggested citation:

Binner, Richard; Homberg, Ulrike; Prohaska, Steffen; Kalbe, Ute; Witt, Karl Josef (2010): Identification of Descriptive Parameters of the Soil Pore Structure using Experiments and CT Data. In: Burns, Susan E.; Bhatia, Shobha K.; Avila, Catherine M. C.; Hunt, Beatrice E. (Hg.): Proceedings 5th International Conference on Scour and Erosion (ICSE-5), November 7-10, 2010, San Francisco, USA. Reston, Va.: American Society of Civil Engineers. S. 397-407. 


\title{
Identification of Descriptive Parameters of the Soil Pore Structure using Experiments and CT Data
}

\author{
Richard Binner', Ulrike Homberg², Steffen Prohaska², Ute Kalbe', \\ and Karl-Josef Witt ${ }^{3}$
}

\begin{abstract}
1BAM Federal Institute for Materials Research and Testing, Berlin, Germany, email: richard.binner@bam.de, ute.kalbe@bam.de

2Zuse Institute Berlin (ZIB), Berlin, Germany, email: homberg@zib.de, prohaska@zib.de

3Bauhaus-Universita”t Weimar, Weimar, Germany, email: kj.witt@uni-weimar.de
\end{abstract}

\begin{abstract}
In this paper, methods are presented that combine experimental and micro tomographic information to derive parameters of the grain and pore structure of wide-gradated soils. For this purpose, samples based on a model soil were prepared for special experiments as well as for high-resolution CT imaging. Compacting and column experiments were developed to determine specific parameters of the pore and grain structure. Among others, the grain size and discharge quantity of potentially mobile grains were identified as well as characteristics of the supporting skeleton of the model.

The results of the compaction and column experiments provide suitable geometric parameters of realistic grain and pore structures for analyzing suffosive erosion phenomena, whereas the CT specimens support the description and visualization of representative pore structures. The presented methods contribute to a better understanding of the physical processes within the pore structure. As a part of the joint project "Conditions of suffosive erosion phenomena in soils", the results of this paper can be incorporated into pore-network models to verify and simulate existing transport models.
\end{abstract}

\section{INTRODUCTION}

Recent extreme flood events suggest that the vulnerability of river basins has increased over the past years as a consequence of climate change and engineering projects. One of the negative results is that any change of flow condition in the subground might trigger internal erosion processes. Any kind of particle displacement represents an evident problem for the stability of retaining constructions, embankment dams, dykes or tailing impontments. In case of unstable structure seepage force can displace the fines within the grain skeleton during groundwater flow. This process is called suffosion and characterizes the relocation 
and discharge of fine particles through the pore space. Soils with a relatively large degree of nonuniformity as well as gap graded soils are particularly prone to suffosion. Initially, the supporting granular skeleton will not be changed. The porosity and permeability of the soil, however, increase. Proceeding suffosion and additional external mechanical influences may cause instabilities of the supporting granular structure and subsequently, other types deformation may occur.

There are some studies on internal erosion (Bonelli et al. 2006, Burns et al. 2006, Fell and Fry 2005, Lachouette et al. 2008, Mattsson et al. 2008, Sjo“ dahl et al. 2008, Vaughan 2000). However, gradated soils have not been included. Furthermore, the combinations of CT analysis with experimental derivation of geometric parameters on pore structures of gradated soils have not been considered. Piping, as a type of internal erosion, was analyzed by (Bonelli et al. 2006, Bryan and Jones 1997, Faulkner 2006, Khilar et al. 1985, Lachouette et al. 2008, Ojha et al. 2001) taking into account only $1 \mathrm{D}$ and $2 \mathrm{D}$ considerations and ignoring spatial and realistic information on the pore space. Although the suffosion controlling parts of the pore structure, characterized by their constriction distribution, is essential to the explanation of suffosion processes (Witt 1986), only the grain size distribution has been used for this purpose in the framework of risk estimation regarding internal erosion.

In this study, spatial and realistic pore structures of gradated soils were investigated. This comprises the preparation of model test material and the generation of 3D CT data sets. Furthermore, experiments were developed in order two determine descriptive parameters on the supporting structure and the mobile fraction.

\section{MATERIAL AND METHODS}

Wide-gradated soils are characterized as coarse grained soils that exhibit an asymmetric grain size distribution. They are frequently prone to be suffosive, especially if they feature a gap grading or a non steady distributed grain size curve. Figure 1 illustrates the model grain size distribution (MGSD) of a suffosive noncohesive soil with a gap grading between 0.63 and $2.8 \mathrm{~mm}$ that was chosen for this study. This kind of distribution is typical for sedimentary soils in the medium course of a large river and is considered as a soil with a high risk for suffosion (Cistin 1967, Witt 1986, Ziems 1969). Model soil samples exhibiting this grain size distribution were processed by sieving. For this purpose, material was taken from a fluviatile soil of the Upper-Rhine river area.

\section{Preparation of samples for $\mathrm{CT}$ analysis and column experiments}

To investigate the spatial structure of gradated soils, samples based on the MGSD were prepared for CT analysis as well as for column experiments. For both approaches, the test samples have to fulfill the following two prerequisites: First, the samples should represent the natural bedding and density of the suffosive material as realistically as possible. Second, the sample volume should be representative and stable. For the CT analysis, the samples were embedded in 
epoxy resin (Figure 2).

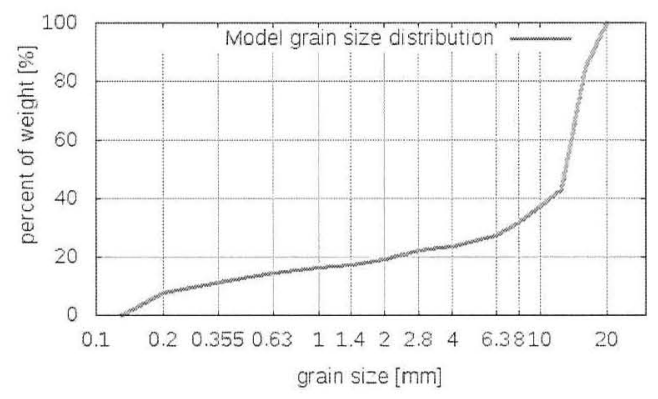

Figure 1: Grain size distribution of the investigated soil.

The individual preparation steps were:

1. Assembling the material: The grain fractions according to the MGSD were merged yielding a mass of $6000 \mathrm{~g}$ and filled into the column. The diameter of the column was $139 \mathrm{~mm}$.

2. Compaction and homogenization: The sample was compacted and homogenized by rotating the column and compressing the material at the same time. This is necessary because the fine grain material has a high mobility in the uncompacted sample. The compaction was achieved by applying a uniform pressure of $2.5 \mathrm{~N} / \mathrm{cm} 2$. For the compression, a plunger was constructed with four springs (Figure 2a-b).

3. Embedding the material: The sample was slowly embedded in epoxy resin from bottom to top in order to avoid air bubbles within the resin and to avoid the relocation of grains (Figure $2 \mathrm{c}$ ).

4. Cutting the sample: The hardened cylindrical sample was cut to a size of $110 \mathrm{~mm}$ in diameter and $110 \mathrm{~mm}$ in height using water jet technique (Figure 2d), taking into account the requirements on the specimen size for CT scans.

A second preparation process was carried out for the column experiments. Step 1 and 2 are analog to the CT preparation steps. The further steps ensure that the column material is permeable to water.

1. Assembling the material.

2. Compaction and homogenization.

3. Inserting a perforated plate: Up to now, a synthetic liner had closed the column during the compaction and homogenization process. The column with the unstressed plunger was rotated and the liner was replaced by a perforated plate and funnel at the bottom of the column (Figure 3c). Both are needed for the column experiment.

4. Inserting a filter layer: A further condition for the experiment is a filter layer 
upon the material. After rotating the column and replacing the plunger, the filter layer was inserted (Figure 3e-f). The filter consists of a perforated plate and a layer of glass spheres. The latter enables a laminar flow during the experiment.

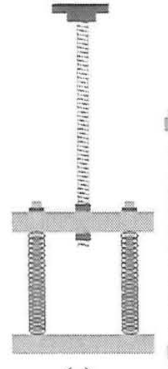

(a)

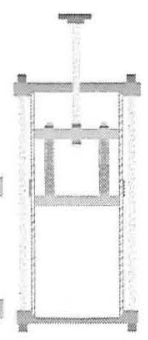

(b)

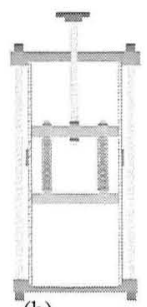

)

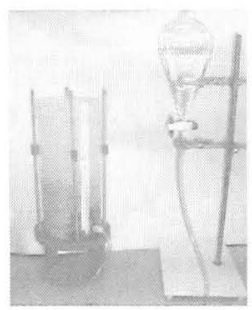

(c)

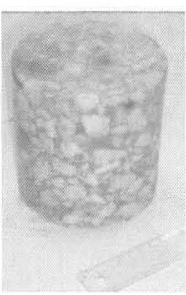

(d)

Figure 2: Preparation of specimens for the CT scan, a) detail of the plunger with the compression springs, b) compaction and homogenization, c) embedding in epoxy resin, d) cylindrical specimen.

\section{CT Analysis}

For analyzing and visualizing the spatial structure of the soil, specimens were prepared for CT analysis. In a previous study (Homberg et al. 2008), specimens of a height and a diameter of $6 \mathrm{~cm}$ each were used and acquired at a resolution of $35 \mu \mathrm{m}$ for analyzing the grains structure. The results show that specimens of $6 \mathrm{~cm}$ diameter cannot be used to determine a representative picture of the geometric structure at the given resolution. Because there is a trade-off between spatial resolution and size of specimen, a double-stage CT acquisition was developed. In a first step, a cylindrical overview specimen of $11 \times 11 \mathrm{~cm}$ was cut out from the original specimen using water jet technique and acquired at a resolution of $209 \mu \mathrm{m}$ (Figure $4 \mathrm{a}-\mathrm{b}$ ). This specimen was cut into 6 parts (Figure $4 \mathrm{c}-$ d). The resulting parts had an edge length of $5.5 \mathrm{~cm}$ and were scanned at a resolution of $39 \mu \mathrm{m}$.

\section{Compaction experiments: Determining the structure-bearing grain fractions}

The aim of this experiment is to determine the grain size fractions that form the supporting skeleton. This experiment was performed assuming that the grain fractions which do not belong to the supporting skeleton will not change the filling height. The filling height $\mathrm{h}$ is the distance between the bottom and the plunger of the column (Figure 5). For this purpose, grain fractions of a $6 \mathrm{~kg}$ sample were split according to the MGSD. Then, the column was filled successively in top down order: 


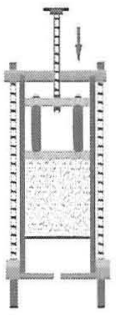

(a)

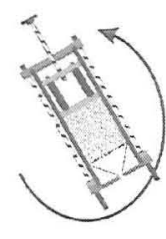

(b)

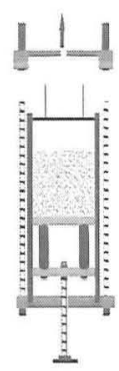

(c)

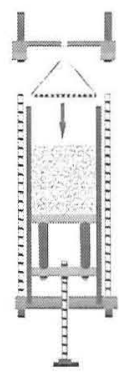

(d)

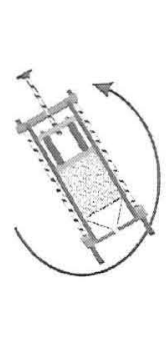

(e)

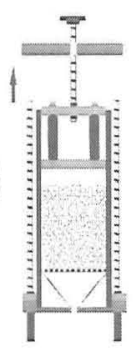

(f)

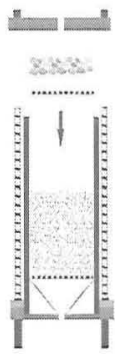

(g)

Figure 3: Workflow of column packing, a) homogenization and compaction, b) turning the column, c-d) replacing the synthetic liner by a perforated plate, e) turning the column, f) replacing the plunger by a perforated plate and $g$ ) inserting a filter layer of glass spheres and a cap with a water inlet.

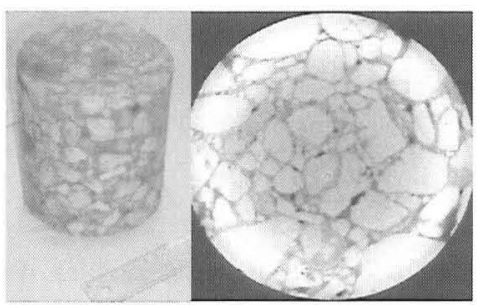

(a)

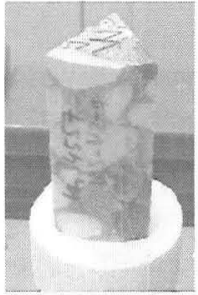

(c)

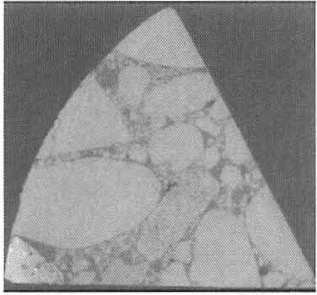

(d)

Figure 4: Double-staged CT scan, a-b) the overview specimen scanned at a resolution of $209 \mu \mathrm{m}, \mathrm{c}-\mathrm{d}$ ) a part cut out from the overview specimen scanned at a resolution of $39 \mu \mathrm{m}$.

from the large fractions to the finer fractions. After each adding step, the material in the column was homogenized and compacted as described in the CT sample preparation. Subsequently, the filling height of the compacted material was measured (Figure 5).

\section{Column experiments: Identification of the mobile grain fractions}

The objective of the experiment is to determine the mobile grain fractions of the MGSD. The assumption is that there are potentially mobile grains within the supporting skeleton and a possible discharge of these grains does not change the supporting skeleton. This experiment was carried out on two samples which were prepared as described in the preparation section. Note that the perforation size of the inserted perforated plate depends on the results of the compaction experiment. That is, the perforated plate has to retain the smallest grain of the supporting skeleton. 


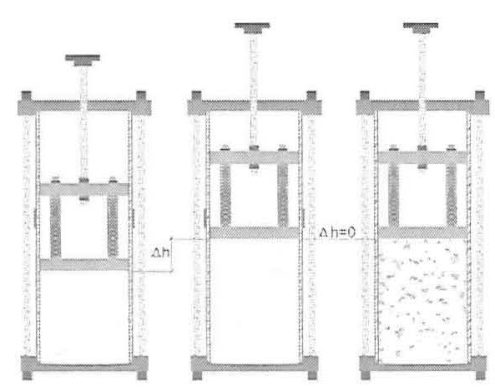

Figure 5: Scheme of the compaction experiment to determine the structure-bearing grain size fractions.

To move the potential mobile grains, water was supplied to the column using an immersion pump at a flow rate of $8.0 \mathrm{l} / \mathrm{min}$ (Figure 6 ). This flow rate corresponds to flow rates within embankment dams, which was found by (Cistin 1967). The discharge containing the mobile grains was collected in a $63 \mu \mathrm{m}$ sieve, which was emptied after certain time intervals $(5,10,30,60 \mathrm{~min}, 24,24,24 \mathrm{~h}$. . .). The experiment was finished when there was no material discharge for $24 \mathrm{~h}$. Finally, the total discharge was analyzed according to (DIN-18123 1996) using sieving sizes of $0.2,0.355,0.63,1.0,1.4,2.0$, and $2.8 \mathrm{~mm}$.

\section{RESULTS}

The compaction experiment was performed for three material samples of the MGSD. The final filling height (sample mass) in the column resulted in $18.9 \mathrm{~cm}$ $(6034 \mathrm{~g}), 18.6 \mathrm{~cm}(5804 \mathrm{~g})$, and $20.0 \mathrm{~cm}$ (6336 g) respectively. Figure 7 shows the filling height per fraction related to the total filling height. The different icons represent three replicates. Regarding the height percentages and the course of the filling height per fraction, one can distinguish three groups:

1. The large fractions $20 / 25$ and $16 / 20 \mathrm{~mm}$ form the main part of the sample with about $80 \%$. They contribute a double-digit height percentage each.

2. The second group consists of the grain fractions of $12.5 / 16 \mathrm{~mm}$ to $4 / 6.3 \mathrm{~mm}$. These fractions nearly complete the filling height up to $99 \%$ in average, whereas each fraction makes up a few percent of the filling height.

3. Finally, there are the finer fractions. Two of the tests had already achieved the full height, whereas one test still converges to the full height. These fractions do not influence the filling height significantly.

The full filling height is composed of the first $(20 / 25$ and $16 / 20 \mathrm{~mm})$ and the second $(12.5 / 16$ to $4 / 6.3 \mathrm{~mm})$ group, whereas the third group smaller than $4 \mathrm{~mm}$ does not contribute to the filling height significantly. They are assumed to be potential mobile within the skeleton of course fractions. In the following, this size of $4 \mathrm{~mm}$ was used to prepare the perforated plate for the column experiment. 


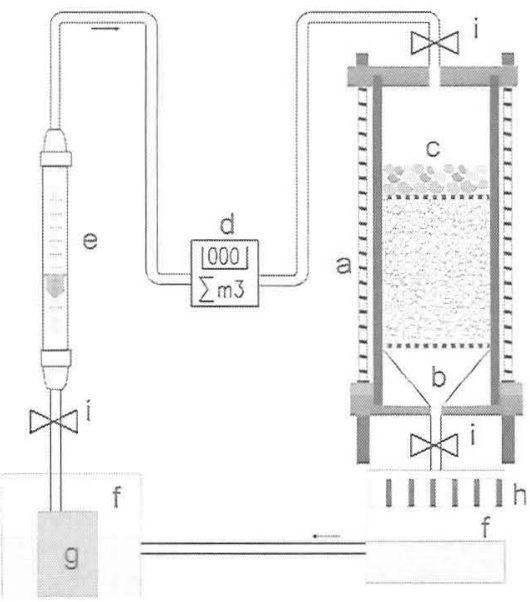

Figure 6: Setup of the column experiment, a) test sample with MSGD, b) perforated plate and funnel, c) layer of glass spheres and perforated plate, d) water meter, e) flow meter, f) water reservoir, g) electric pump, h) sieve, i) plug cock.

Two replicates of the column experiment were carried out, lasting about $70 \mathrm{~h}$. Figure 8 shows the percentage per fraction that was discharged as well as the entire discharge related to the total sample mass. Again, one can distinguish three groups. In the first group, the discharge dominates. Nearly two-thirds and more than a half of the fine fractions $0 / 0.335$ and $0.335 / 0.63 \mathrm{~mm}$ were discharged. That is, one-third to a half of these fractions was retained during the experiment. For the second group, the retained percentage dominates. It contains the fractions between 0.63 to $2.8 \mathrm{~mm}$. The discharge ranges from 8 to $34 \%$. Third, the fraction $2.8 / 4.0 \mathrm{~mm}$ exhibit sparse discharges: $2.2 \%$ and $1.4 \%$, respectively.

The prepared $\mathrm{CT}$ scans allow visualizing the structures of the investigated soil. The overview scan reveals the whole structure at a low resolution (Figure 4b). Finer structures can be viewed using the detailed scans, which contain the structure parts of the overview scan at a higher resolution (Figure 4d). Figure 9 shows 4 detailed slices out of a CT scan in lateral view, which represent $22 \times 22 \mathrm{~mm}$ each and are taken from a range of $3.3 \mathrm{~mm}$. The slices show 4 large grains of the fractions $12.5 / 16$ and $16 / 20 \mathrm{~mm}$. These large grains form cavities, wherein small grains of the fractions $0.335 / 0.63$ to $2 / 2.8 \mathrm{~mm}$ were enclosed.

\section{DISCUSSION}

Considering the results of the experiments, the grains of the MGSD can be distinguished by their behavior during suffosion processes: structure-bearing, mobile, and retained grains. The compaction experiments showed which grain fractions influence the filling height and form the supporting skeleton, respectively. 


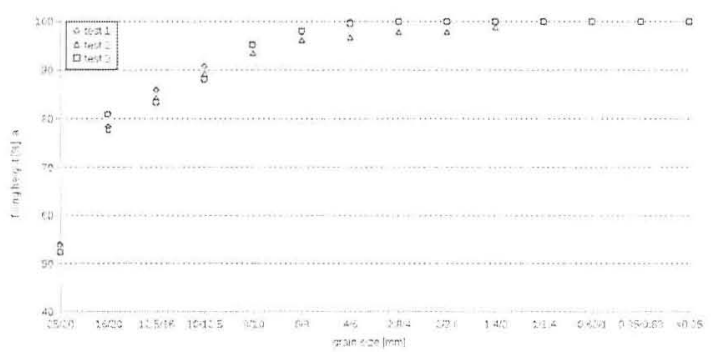

Figure 7: Compaction experiment: filling height per fraction related to the total filling height.

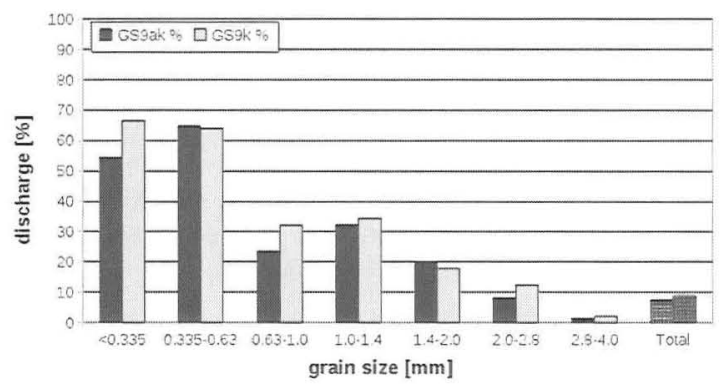

Figure 8: Column experiment: percentage of discharge per fraction and final discharge related to the total sample mass.

Transformed to erosion phenomena this test procedure corresponds to volume change due to a successive erosion of fines. As there is no or less volume change, the eroded particles are embedded within the space of the statical overall structure without fixing. The test shows that the supporting skeleton is dominated by the fractions from $20 / 25$ to $4 / 6.3 \mathrm{~mm}$. The grain of these fractions governs the structure. The remaining fractions are embedded and potential mobile. That is, they can be discharged or retained depending of the opening size of the structure. The column experiment identifies the mobile and the retained grains of the potential mobile fractions. The resulting groups of this experiment were distinguished by their discharged percentage. The first group exhibits the largest discharge and thus a high mobility. The pore structure mostly seems to consist of connected pore paths with constrictions equal or larger than $0.63 \mathrm{~mm}$. The second group has a minor discharge and thus shows a lower mobility. This indicates that the pore structure contains only a few preferential paths with adequate sized constrictions related to the particular fractions. Considering possible boundary effects and measuring uncertainties, the discharge of the third group (fraction $2.8 / 4 \mathrm{~mm}$ ) is too sparse to assign it to the mobile fraction. 


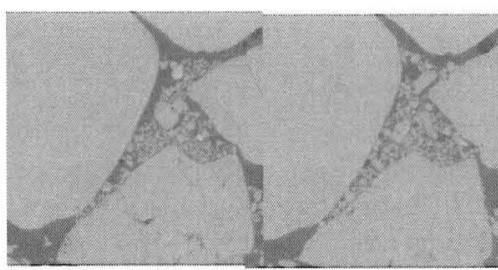

(a)

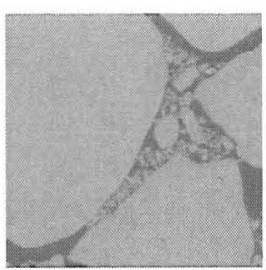

(c)

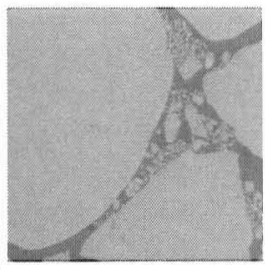

(d)

Figure 9: Potential mobile grains retained by structure-bearing grains in a detail of $22 \times 22$ $\mathrm{mm}$ at a resolution of $39 \mu \mathrm{m}$

That is, the largest mobile grains are $2.8 \mathrm{~mm}$. The results of the column experiments suggest that the two smallest fractions are highly mobile in the entire pore space. The complete percentage of these fractions was not discharged. This is due to the irregular shape of real grains and their arrangement, possibly. The analysis of the CT scans encourages this suspicion (Figure 9). The large grains contain concave, convex, and flat surfaces that form cavities and gaps, which retain the potential mobile grains. The mobility could be investigated shape independent using samples of glass spheres to estimate the order of magnitude of this effect. As discussed above, the fraction of $2.8 / 4 \mathrm{~mm}$ can be assigned neither to the overall mobile fractions nor to the structure-bearing fractions. The fraction seems to be a transition between both of them embedded into the coarser pore space of the structure. Possibly, the boundary is located somewhere in this size range. To narrow down this boundary, this fraction could be subdivided into smaller fractions for further experiments. On the other hand, possible boundary effects may appear because the perforated plate does not represent the structure of soil and may impact the soil structure at the bottom of the sample and thus the discharge of this region. This could be investigated with different samples masses or different perforated plates. Furthermore, the results of the compaction experiments exhibit some uncertainty in the range of the lower skeleton boundary and should be validated by further experiments.

\section{CONCLUSIONS}

Methods for preparing soil samples and generating CT data as well as experiments that determine geometrical parameters of gradated soils were presented. A compaction experiment was designed and replicated to approximate the lower size boundary of the statically structure-bearing grain fractions. It separates the structurebearing fractions that might be the effective grain size distribution related to the common criteria from the potentially mobile fractions which not contribute to the structure. This boundary further was used to design the column experiment. By means of the column experiment, the potentially mobile fractions were analyzed by 
determining the percentages of the mobile and the retained grains. This led to the size of the largest mobile grains within the soil structure and moreover to a size boundary between high mobile and less mobile fractions. In turn, this allows drawing conclusions on the relevant pore structure concerning its connectivity and constriction sizes. The double-staged CT scans allow capturing large and representative specimens at a high resolution. By transforming the scans into a mathematical and numerical model this technique can be used to estimate and analyze the spatial soil structures visually.

\section{ACKNOWLEDGEMENTS}

The authors thank the German Research Foundation (DFG) for supporting the research project "Conditions of suffosive erosion phenomena in soil".

\section{REFERENCES}

Bonelli, S., Brivois, O., Borghi, R., and Benahmed, N. (2006). "On the modelling of piping erosion.” Comptes Rendus M'ecanique, 334(8-9), 555-559.

Bryan, R. B. and Jones, J. A. A. (1997). "The significance of soil piping processes: inventory and prospect." Geomorphology, 20(3-4), 209-218.

Burns, B., Barker, R., and Ghataora, G. S. (2006). "Investigating internal erosion using a miniature resistivity array." NDT \& E International, 39(2), 169-174.

Cistin, J. (1967). „Zum Problem mechanischer Deformation nichtbindiger Lockergesteine durch die Sickerwasserstr" omung in Erdd"ammen." Wasserwirtschaft Wassertechnik, 2, 45-49. DIN-18123. (1996)., Bestimmung der Korngr"oßenverteilung.” DIN Deutsches Institut für Normung e.V., 11.

Faulkner, H. (2006). "Piping Hazard on Collapsible and Dispersive Soils in Europe.” Soil Erosion in Europe, J. B. a. J. Poesen, ed., 537-563.

Fell, R. and Fry, J.-J. (2005).'’Internal Erosion of Dams and their Foundations." Aussois. Homberg,

U., Binner, R., Prohaska, S., Dercksen, V. J., Kuß, A., and Kalbe, U. (2008). "Determining Geometric Grain Structure from X-Ray Micro-Tomograms of Gradated Soil." In Witt, K.-J. editor (2008), Proc. Work. Internal Erosion, Weimar.

Khilar, K. C., Fogler, H. S., and Gray, D. H. (1985). "Model for Piping-Plugging in EarthenStructures." Journal of Geotechnical Engineering, 111(7), 833-846

Lachouette, D., Golay, F., and Bonelli, S. (2008). "One-dimensional modeling of piping flow erosion." Comptes Rendus M'ecanique, 336(9), 731-736.

Mattsson, H., Hellstr" om, J. G. I., and S., L. T. (2008). "On Internal Erosion in Embakment Dams." University of Technology, Lulea.

Ojha, C. S. P., Singh, V. P., and Adrian, D. D. (2001). "Influence of porosity on piping models of levee failure." Journal of geotechnical and geoenvironmental engineering (12), 1071-1074.

Sj”odahl, P., Dahlin, T., Johansson, S., and Loke, M. H. (2008). "Resistivity monitoring for leakage and internal erosion detection at $\mathrm{H}^{*}$ allby embankment dam." Journal of Applied Geophysics, 65(3-4), 155-164. 
Vaughan, P. R. „Internal Erosion of Dams Assessment of Risks.” Filters and Drainage in Geotechnical and Environmental Engineering on the 3th International Conference Geofilters, Warszawa, Rotterdam, 349-356.

Witt, K.-J. (1986). „Filtrationsverfahren und Bemessung von Erdstofffiltern.” Universit" at Karlsruhe, Karlsruhe.

Ziems, J. (1969). „Beitrag zur Kontakterosion nichtbindiger Erdstoffe.” TU Dresden. 